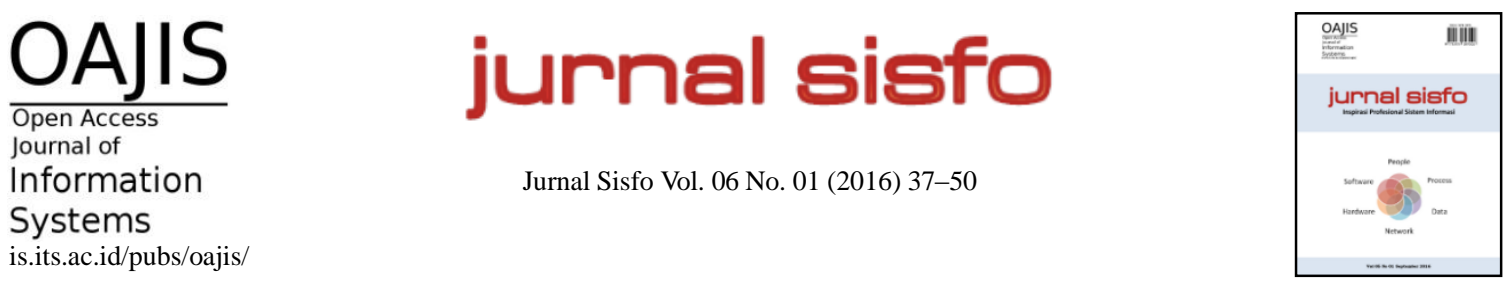

\title{
Penerapan Sistem Informasi Berbasis Enterprise Resource Planning Menggunakan SAP Modul Plant Maintenance di PT. Len Industri
}

\author{
Dwi Pratama*, Wahjoe Witjaksono, Nia Ambarsari \\ Program Studi Sistem Informasi, Fakultas Rekayasa Industri, Telkom University
}

\begin{abstract}
Main problem of plant maintenance business process on PT. Len Industri (Persero) are absence of maintenance activities documentation storage and no real time machine availability status. The right solution is implement ERP systems that applies a centralized database, so data can be stored properly and maintenance process can be integrated with the relevant sections. One of ERP vendor that provides solution for plant maintenance is SAP. This SAP ERP implementation using ASAP with the stages are problem identification, goal setting, current business process analysis, SAP ERP business process analysis, configuration and system testing. After configuration phase, all maintenance process can be accommodated by SAP with adjustments needed by the company. Based on the configuration and application testing. SAP ERP can be applied to the PT. Len Industri (Persero).
\end{abstract}

Keywords: ERP, SAP, Plant Maintenance, ASAP method

\begin{abstract}
Abstrak
Permasalahan kegiatan pemeliharaan mesin dan peralatan produksi yang terdapat pada PT. Len Industri (Persero) permasalahan yaitu tidak terdapatnya tempat penyimpanan riwayat kegiatan pemeliharaan dan notifikasi status ketersediaan mesin secara real time. Solusi yang tepat untuk permasalahan tersebut yaitu dengan mengembangkan sistem ERP yang menerapkan sistem database terpusat sehingga data tersimpan dengan baik dan kegiatan pemeliharaan dapat terintergrasi dengan bagian terkait. Salah satu vendor ERP yang menyediakan solusi untuk kegiatan pemeliharaan mesin adalah SAP dengan modul Plant Maintenance. Penerapan SAP ERP ini menggunakan metode ASAP dengan tahapan yaitu perumusan masalah, penentuan tujuan, analisis proses bisnis saat ini, analisis proses bisnis SAP ERP, analisis gap fit, analisis risiko, konfigurasi dan pengujian aplikasi. Berdasarkan konfigurasi dan pengujian sistem yang dilakukan, SAP ERP dapat diterapkan pada PT. Len Industri (Persero).
\end{abstract}

Kata kunci: ERP, SAP, Pemeliharaan Mesin dan Peralatan Produksi, Metode ASAP

(C) 2016 Jurnal SISFO.

Histori Artikel : Disubmit 10 Juni 2016; Diterima 14 Juli 2016; Tersedia online 24 Agustus 2016

${ }^{*}$ Corresponding Author

Email address: dwipratama14@gmail.com (Dwi Pratama) 


\section{Pendahuluan}

PT Len Industri (Persero) merupakan Badan Usaha Milik Negara (BUMN) yang didirikan berdasarkan Peraturan Pemerintah Indonesia No. 16 Tahun 2002 yang bergerak dalam bidang usaha elektronika untuk industri dan prasarana dengan memiliki enam lini bisnis, yaitu Renewable Energy, Railway Transport, Information and Communication Technology, Defense Electronics, dan Navigation System. PT. Len Industri (Persero) memproduksi banyak jenis produk dengan nilai proyek mencapai Rp. 1.921.476.970[1]. Untuk merealisasikan nilai proyek yang telah didapatkan, PT. Len Industri (Persero) melakukan investasi mesin dan peralatan produksi sebesar Rp. 11.022.000.000 pada tahun [1]. Dengan besarnya investasi yang telah dikeluarkan, perlu adanya sebuah pemeliharaan mesin dan peralatan produksi agar tercipta kelancaran proses produksi disetiap lini bisnis PT. Len Industri (Persero).

Kegiatan pemeliharaan mesin dan peralatan produksi yang terdapat di PT. Len Industri (Persero) terbagi menjadi dua, yaitu preventive maintenance (pencegahan) dan curative maintenance (penanggulangan). Namun kegiatan tersebut tidak dilakukan dengan prosedur baku karena belum adanya SOP (Standard Operating Procedure) yang menjadi standar pelaksanaan dari kegiatan pemeliharaan mesin dan peralatan produksi. Dokumentasi disetiap kegiatan pemeliharaan mesin dan peralatan produksi hanya dilakukan dengan menggunakan kartu gantung pemeliharaan disetiap mesin, tentu hal ini sangat rentan akan kerusakan dan kehilangan dari kartu tersebut yang dapat menyebabkan riwayat pemeliharaan tidak terdokumentasi dengan baik. Selain itu, tidak adanya pemberitahuan status ketersedian mesin dan peralatan produksi yang akan digunakan secara real time sehingga dapat menyebabkan terganggunya aktifitas produksi PT. Len Industri (Persero).

Berdasarkan permasalahan tersebut, pengimplementasian Enterprise Resource Planning (ERP) dapat menjadi salah satu solusi. ERP adalah perangkat lunak yang digunakan oleh perusahaan untuk mengintegrasikan dan mengkoordinasikan informasi disetiap area bisnis perusahaan. Sistem ERP menggunakan sebuah database umum yang dapat diakses oleh masing-masing area bisnis, sehingga aliran informasi operasional dari sebuah perusahaan dapat termonitor dengan baik dan tidak terdapat duplikasi informasi. Integrasi departemen yang dihasilkan setelah penerapan sistem ERP dapat mempercepat proses pekerjaan baik didalam suatu departemen atau lintas departemen sebuah perusahaan. Terdapat banyak penyedia sistem ERP, salah satunya adalah SAP (System, Applications, Production in Data Processing) yang menyediakan beberapa modul ERP yang dapat digunakan perusahaan sesuai dengan kebutuhannya, salah satunya adalah Plant Maintenance yang relevan dengan permasalahan di PT. Len Industri (Persero).

Masalah yang terjadi dalam kegiatan pemeliharaan mesin dan peralatan produksi PT. Len Industri (Persero) dapat dirumsukan dengan bagaimana mengembangkan sistem SAP ERP modul plant maintenance di PT. Len Industri (Persero) sebagai solusi permasalahan yang ada, bagaimana software SAP ERP modul plant maintenance dapat menyimpan dokumentasi pencatatan riwayat kegiatan pemeliharaan mesin produksi dan mengeluarkan pemberitahuan status ketersediaan mesin produksi secara real time, serta bagaimana bagian lain dalam divisi produksi dan divisi lain yang berkaitan dengan bagian pengendali fasilitas produksi dapat saling berintegasi.

Berdasarkan perumusan masalah tersebut, maka penelitian ini bertujuan untuk menyediakan dokumentasi SOP (Standard Opertional Procedure) kegiatan pemeliharaan mesin dan peralatan produksi, menyediakan dokumentasi pencatatan riwayat kegiatan pemeliharaan mesin dan peralatan produksi, dan menyediakan sistem terintegrasi untuk ketersedian mesin dan peralatan produksi antar bagian terkait.

Adapun maanfaat yang diperoleh dari penelitian ini yaitu terciptanya integrasi informasi pada divisi produksi PT. Len Industri (Persero), adanya SOP (Standard Operating Procedure) yang menjadi standar pelaksanaan kegiatan pemeliharaan mesin dan peralatan produksi, dan adanya dokumentasi riwayat kegiatan pemeliharaan mesin dan peralatan produksi yang baik sehingga menjadi acuan untuk kegiatan pemeliharaan selanjutnya. 


\section{Tinjauan Pustaka/Penelitian Sebelumnya}

\subsection{Sistem Informasi}

Sistem informasi adalah seperangkat komponen yang saling terhubung untuk mengumpulkan (input), memanipulasi (proses), menyimpan, dan menyebarkan (output) data dan informasi untuk membantu pencapaian tujuan sebuah organisasi [2]. Setiap kegiatan operasional yang terjadi pada sebuah organisasi atau perusahaan membutuhkan pengelolaan data dan informasi secara cepat dan tidak terdapat duplikasi data. Dengan penerapan sistem informasi, hal tersebut dapat terpenuhi karena keterhubungan masingmasing komponen didalamnya.

Komponen dalam sistem informasi yang dimaksud dapat diklasifikasikan sebagai berikut: hardware, software, database, network, people, dan procedures. Hardware merupakan komponen yang digunakan untuk kegiatan input, porses, dan output dalam sistem informasi seperti keyboard, Central Processing Unit (CPU), dan printer. Software merupakan komponen yang digunakan untuk mengoperasikan komputer dalam kegiatan sistem informasi seperti Microsoft Windows. Database merupakan komponen yang digunakan untuk menyimpan data dan informasi dalam sistem informasi. Network merupakan komponen yang digunakan untuk media komunikasi dalam sistem informasi seperti Internet. People merupakan komponen yang melakukan kegiatan input, proses dan output dalam sistem informasi dengan memanfaatkan komponen sistem informasi lainnya. Procedures merupakan komponen yang mengatur kegiatan input, proses dan output dalam sistem informasi sesuai yang berlaku dalam suatu organisasi.

\subsection{Enterprise Resource Planning (ERP)}

Merupakan sistem yang digunakan oleh perusahaan untuk mengintegrasikan dan mengkoordinasikan informasi di setiap fungsional bisnis. ERP membantu perusahaan mengatur aktivitas bisnis dengan menggunakan sebuah database umum yang dapat diakses dari setiap fungsional bisnis [3]. Implementasi ERP pada sebuah perusahaan harus didukung penuh oleh manajemen perusahaan [4]. Dukungan dari manajemen sangat mempengaruhi implementasi ERP karena manajemen merupakan pihak yang bertugas untuk tetap menyelaraskan sistem yang berjalan dengan tujuan perusahaan. Pelatihan karyawan terhadap sistem ERP yang telah diimplementasikan merupakan salah satu peran manajemen agar sistem ERP dapat berjalan dengan baik.

ERP merupakan perkembangan dari sistem Manufacturing Resource Planning (MRP II) yang belum dapat mengintegrasikan kegiatan manufacturing dengan fungsional bisnis lain yang terkait seperti finance, sales, marketing, dan distribusi produk ke pelanggan. Sistem ERP menyediakan beberapa proses yang dapat perusahaan gunakan sesuai dengan kebutuhannya, seperti: logistik, Production Planning and Control, Purchasing, Sales, Finance, dan Human Resources Management [5].

\subsection{Plant Maintenance}

Plant maintenance adalah sebuah aktifitas teknis dan administrasi yang dilakukan untuk menjaga dan memperbaiki mesin serta peralatan sehingga dapat berfungsi sesuai dengan fungsinya dengan empat aktivitas yaitu Inspection, Maintenance, Repair, dan Improvement [6]. Inspection adalah aktivitas untuk memastikan fungsi mesin berjalan sebagaimana mestinya, menjadualkan pemeriksaan rutin terhadap suatu mesin dan menentukan aktivitas-aktivitas apa saja yang dibutuhkan untuk pemeliharaan mesin tersebut [6].

Maintenance adalah aktivitas perawatan mesin dengan tugas-tugas berikut: penggantian komponen mesin secara berkala, pembersihan mesin secara berkala, pelumasan mesin secara berkala, dan melakukan function test agar fungsi mesin tetap terjaga dalam menjalankan tugasnya [6]. Repair adalah aktivitas untuk perbaikan ketika mesin mengalami suatu masalah sehingga dapat berfungsi sesuai dengan fungsinya 
Improvement adalah aktivitas untuk meningkatkan aktivitas-aktivitas yang terdapat pada plant maintenance sehingga kondisi mesin dapat terjaga tanpa merubah fungsional dari mesin [6].

\section{Metodologi}

Accelerate SAP (ASAP) adalah sebuah metodologi yang diluncurkan SAP untuk memandu dalam implementasi aplikasi SAP ERP yang terdiri dari lima tahap yaitu sebagai berikut [7]:

\section{1) Project Preparation}

Pada tahap ini akan dilakukan perencanaan penelitian dengan mendefinisikan ruang lingkup permasalahan yang ada, menentukan tujuan penelitian, dan mengumpulkan data-data terkait yang diperlukan dalam penelitian ini. Dalam penentuan perencanaan penelitian ini, peneliti melakukan rapat bersama Manajer Divisi Sistem Informasi dan Divisi Produksi PT. Len Industri (Persero). Hasil dari penentuan perencaan penelitian ini adalah data terkait penelitian seperti data work center, data mesin dan peralatan produksi, data komponen mesin, data Functional Location, data komponen mesin.

2) Business Blueprint

Pada tahap ini akan dilakukan analisis tentang kondisi perusahaan saat ini berupa analisis tentang proses bisnis yang diberlakukan saat ini dan analisis tentang proses bisnis SAP ERP. Dalam analisis kondisi saat ini dalam perusahaan, peneliti melakukan wawancara dengan Manajer Produksi dan Koordinator Bagian Pengendali Fasilitas Produksi PT. Len Industri (Persero) sehingga menjadi dokumen As Is. Sedangkan untuk analisis proses bisnis SAP ERP, peneliti menganalisis berdasarkan proses bisnis SAP ERP modul Plant Maintenance berdasarkan sumber yang peneliti gunakan sehingga menjadi dokumen To Be. Dokumen As Is dan To Be akan digunakan untuk menyusun, analisis gap, proses bisnis usulan untuk perusahaan dan melakukan konfigurasi pada aplikasi SAP ERP. Analisis gap dilakukan dengan melakukan perbandingan proses bisnis As Is apakah dapat diakomodasi oleh proses bisnis SAP ERP sehingga akan ditetapkan keputusan yaitu standarisasi (terakomodasi) atau kustomisasi (tidak terakomodasi dan harus dilakukan penyesuaian terhadap aplikasi). Setelah itu akan dilakukan analisis risiko untuk implementasi aplikasi SAP ERP ini dengan mengacu pada poin-poin pertanyaan yang terdapat dalam sumber yang digunakan peneliti. Setelah itu peneliti akan melakukan wawancara terhadap Manajer Sistem Informasi, Manajer Produksi dan Koordinator Pengendali Fasilitas dengan mengajukan pertanyaan risiko yang telah disusun.

3) Realization

Pada tahap ini akan dilakukan konfigurasi pada aplikasi SAP ERP modul Plant Maintenance berdasarkan Business Blueprint yang telah dibuat sebelumnya. Konfigurasi dilakukan oleh peneliti dengan mengacu pada dokumen Business Blueprint yang telah dibuat tanpa berhenti berkomunikasi dengan Manajer Divisi Sistem Informasi, Manajer Produksi, dan Koordinator Bagian Pengendali Fasilitas Produksi PT. Len Industri (Persero) untuk melakukan konfirmasi bahwa konfigurasi yang dilakukan sesuai dengan kebutuhan perusahaan.

\section{4) Final Preparation}

Pada tahap ini akan dilakukan User Acceptance Testing untuk menguji aplikasi SAP ERP apakah sudah sesuai dengan kebutuhan perusahaan. Peneliti melakukan pengujian aplikasi kepada calon user yaitu Koordinator dan staf Bagian Pengendali Produksi PT. Len Industri (Persero).

5) Go Live \& Support

Pada tahap ini aplikasi SAP ERP dinyatakan siap Go Live setelah pengujian aplikasi diterima oleh calon user.

Selain metodologi ASAP yang dibutuhkan dalam pengembangan aplikasi SAP ERP, dibutuhkan juga kerangka berpikir yang dapat menggambarkan metode dalam memecahkan masalah pada penelitian ini secara terstruktur yang dapat disebut dengan model konseptual. Gambar 1 menjelaskan model konseptual yang digunakan. Kegiatan pemeliharaan mesin dan peralatan produksi terdapat lima aktivitas didalamnya yang melewati fase masukan, proses, dan keluaran. 


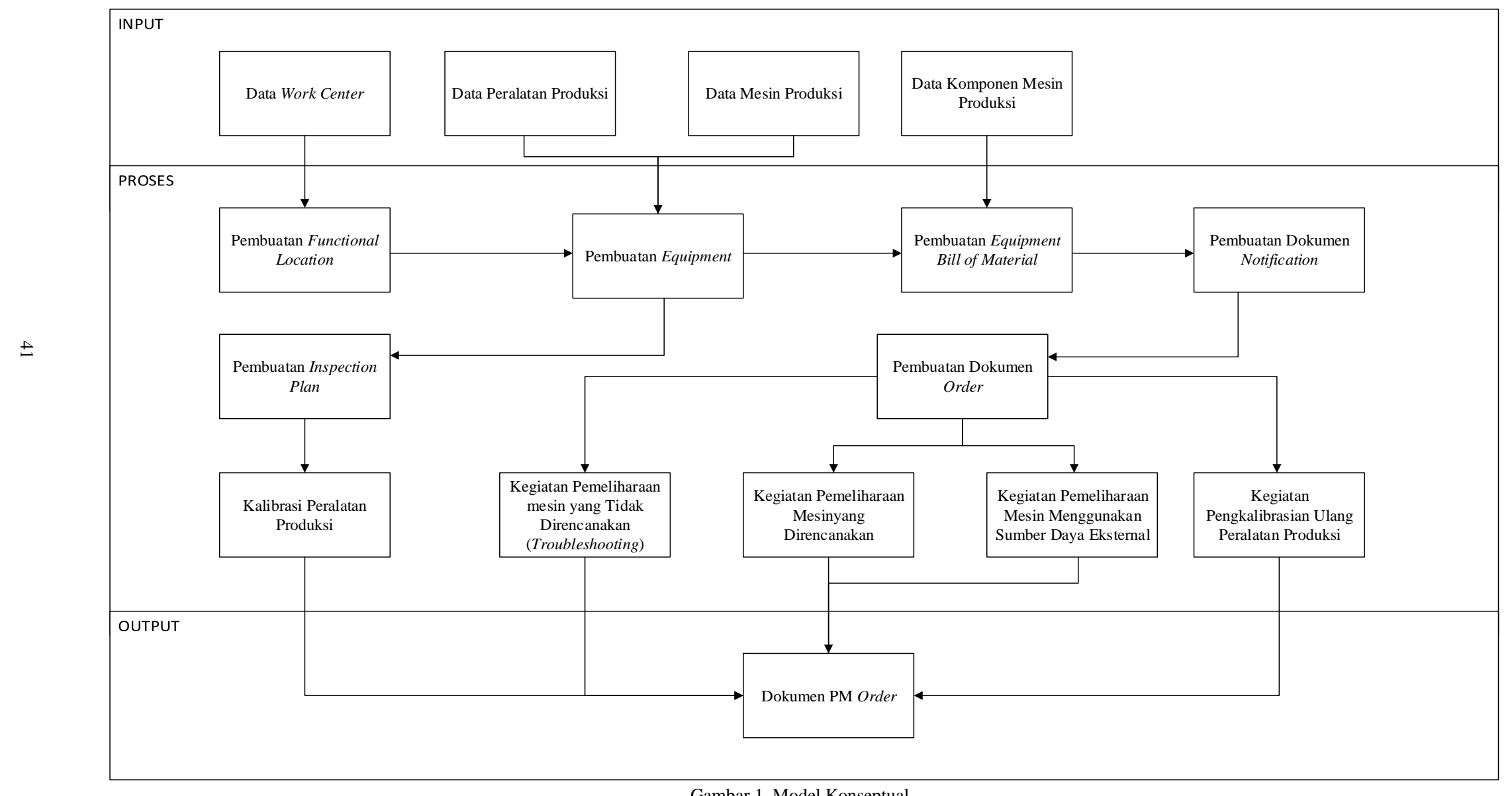


Aktifitas - aktifitas pada Gambar 1, secara lebih jelas digambarkan sebagai berikut :

1) Data Work Center

Pendefinisian data Work Center yang berlaku pada divisi produksi PT. Len Industri (Persero) ke dalam aplikasi SAP ERP berdasarkan hasil wawancara peneliti dengan Manajer Produksi dan Koordinator Pengendali Fasilitas Produksi

2) Data Mesin Produksi

Pendefinisian data mesin produksi yang terdapat pada PT. Len Industri (Persero) ke dalam aplikasi SAP ERP berdasarkan hasil wawancara peneliti dengan Manajer Produksi dan Koordinator Pengendali Fasilitas Produksi.

3) Data Peralatan Produksi

Pendefinisian data peralatan produksi yang terdapat pada PT. Len Industri (Persero) ke dalam aplikasi SAP ERP berdasarkan hasil wawancara peneliti dengan Manajer Produksi dan Koordinator Pengendali Fasilitas Produksi.

4) Data Komponen Mesin Produksi

Pendefinisian data komponen mesin produksi yang terdapat pada PT. Len Industri (Persero) ke dalam aplikasi SAP ERP berdasarkan hasil wawancara peneliti dengan Manajer Produksi dan Koordinator Pengendali Fasilitas Produksi.

5) Pendefinisian Functional Location

Pendefinisian hirarki dari tempat fungsional pemeliharaan peralatan produksi yang terdapat pada divisi produksi PT. Len Industri (Persero) ke dalam aplikasi SAP ERP berdasarkan hasil wawancara peneliti dengan Manajer Produksi dan Koordinator Pengendali Fasilitas Produksi.

6) Pendefinisian Equipment

Pendefinisian data mesin dan peralatan produksi ke dalam aplikasi SAP ERP berdasarkan hasil wawancara peneliti dengan Manajer Produksi dan Koordinator Pengendali Fasilitas Produksi.

7) Pendefinisian Equipment Bill of Material

Pendefinisian data komponen dari sebuah mesin dan peralatan produksi yang terdapat pada divisi produksi PT. Len Industri (Persero) ke dalam aplikasi SAP ERP berdasarkan hasil wawancara peneliti dengan Manajer Produksi dan Koordinator Pengendali Fasilitas Produksi.

8) Pembuatan Dokumen Notification

Pembuatan Dokumen Notification yang berisi data kerusakan yang terjadi pada mesin atau peralatan produksi dengan menggunakan aplikasi SAP ERP. Dokumen Notification digunakan dalam melakukan kegiatan pemeliharaan mesin dan peralatan produksi.

9) Pembuatan Dokumen Inpection Plan

Pembuatan Dokumen Inspection Plan sebagai dasar melakukan kegiatan kalibrasi ulang peralatan produksi dengan menggunakan aplikasi SAP ERP. Dokumen Inspection Plan digunakan dalam melakukan kegiatan kalibrasi peralatan produksi.

10)Pembuatan Dokumen Order

Pembuatan Dokumen Order sebagai dasar melakukan kegiatan pemeliharaan mesin serta pengkalibrasian ulang dengan menggunakan aplikasi SAP ERP. Dokumen Order digunakan dalam melakukan kegiatan pemeliharaan mesin dan peralatan produksi.

11) Kalibrasi Peralatan Produksi

Suatu kegiatan untuk memastikan setiap peralatan produksi yang digunakan sesuai dengan standar yang sudah ditetapkan.

12) Pemeliharaan Mesin yang Direncanakan

Suatu kegiatan pemeliharaan mesin produksi yang telah dijadwalkan oleh bagian fasilitas divisi produksi PT. Len Industri (Persero).

13)Pemeliharaan Mesin yang Tidak Direncanakan (Troobleshooting)

Suatu kegiatan penanggulangan kerusakan mesin produksi oleh bagian fasilitas divisi produksi PT. Len Industri (Persero).

14)Pemeliharaan Mesin yang Melibatkan Sumber Daya Eksternal

Suatu kegiatan pemeliharaan mesin produksi oleh bagian fasilitas divisi produksi PT. Len Industri (Persero) yang melibatkan teknisi atau operator dari vendor mesin produksi terkait. 
15)Dokumen PM Order

Suatu dokumen laporan dari setiap kegiatan pemeliharaan mesin dan peralatan produksi

\section{Hasil dan Pembahasan}

Berikut merupakan hasil dan pembahasan dari penerapan ERP menggunakan SAP dalam kegiatan pemeliharaan mesin dan peralatan produksi.

\subsection{Hasil}

Pada penelitian ini dilakukan penyesuaian kebutuhan PT. Len Industri (Persero) terkait kegiatan pemeliharaan mesin dan peralatan produksi terhadap aplikasi SAP ERP. Tahapan pertama adalah melakukan identifikasi kebutuhan fungsional yang dapat dilakukan user pada aplikasi SAP ERP dan digambarkan pada Use Case Diagram. Selanjutnya akan digambarkan hasil identifikasi urutan aktivitas user berdasarkan fungsional yang telah diidentifikasi melalui Activity Diagram. Setelah melakukan identifikasi kebutuhan fungsional dan urutan aktivitas user, akan dilakukan Baseline Configuration yaitu konfigurasi terhadap aplikasi SAP ERP berdasarkan identifikasi fungsional yang sudah dilakukan dan dokumen Best Practice yang disediakan oleh SAP. Konfigurasi yang dilakukan terbagi menjadi tiga bagian yaitu sebagai berikut:

1) Pendefinisian Enterprise Structure

Pada bagian ini didefinisikan company profile yang berlaku pada PT. Len Industri (Persero) seperti define company dan define plant.

2) Pendefinisian Plant Maintenance Master Data

Pada bagian ini didefinisian data dasar yang akan digunakan pada kegiatan pemeliharaan mesin dan peralatan produksi seperti Work Center, Equipment, dan Functional Location.

3) Konfigurasi Plant Maintenance Procedure.

Pada Bagian ini dijelaskan prosedur penggunaan aplikasi SAP ERP untuk setiap kegiatan pemeliharaan mesin dan peralatan produksi.

Setelah melakukan Baseline Configuration, tahap selanjutnya adalah melakukan User Acceptance Testing untuk memastikan bahwa aplikasi SAP ERP sesuai dengan kebutuhan dari PT. Len Industri (Persero). Pengujian ini dilakukan dengan user menjalankan salah satu proses bisnis kegiatan pemeliharaan mesin dan peralatan produksi berdasarkan prosedur modul Plant Maintenance yang sudah dibuat. Apabila hasil yang sesuai dengan test scenario maka kolom result akan dilakukan pemberian tanda checklist, apabila tidak akan dilakukan pemeberian tanda silang. User Acceptance Testing digambarkan pada Tabel 1.

Tabel 1. Hasil User Acceptance Testing

\begin{tabular}{|c|c|c|c|c|c|}
\hline No. & Modul & Test Scenario & Expected Result & Result & Remarks \\
\hline \multirow{4}{*}{1.} & \multirow{4}{*}{$\begin{array}{l}\text { Creating } \\
\text { Notification } \\
\text { Document }\end{array}$} & \multirow{4}{*}{$\begin{array}{l}\text { Pencatatan informasi } \\
\text { penyebab kerusakan mesin }\end{array}$} & $\begin{array}{l}\text { Terdapat informasi tentang mesin } \\
\text { yang mengalami kerusakan }\end{array}$ & $\sqrt{ }$ & \\
\hline & & & $\begin{array}{c}\text { Terdapat informasi kerusakan } \\
\text { mesin }\end{array}$ & $\sqrt{ }$ & \\
\hline & & & $\begin{array}{l}\text { Terdapat informasi waktu } \\
\text { terjadinya kerusakan mesin }\end{array}$ & $\sqrt{ }$ & \\
\hline & & & $\begin{array}{c}\text { Terdapat informasi siapa } \\
\text { penanggung jawab dari mesin } \\
\text { tersebut }\end{array}$ & $\sqrt{ }$ & \\
\hline
\end{tabular}


Dwi Pratama et al. / Jurnal SISFO Vol.06 No.01 (2016) 33-48

\begin{tabular}{|c|c|c|c|c|c|}
\hline No. & Modul & Test Scenario & Expected Result & Result & Remarks \\
\hline 2. & $\begin{array}{c}\text { Release Notifiaction } \\
\text { Document }\end{array}$ & $\begin{array}{c}\text { Melakukan release } \\
\text { dokumen notification untuk } \\
\text { menjadi dokumen } \text { order } \\
\text { sebagai detail operasi } \\
\text { pemeliharaan }\end{array}$ & $\begin{array}{l}\text { Dokumen notification dapat } \\
\text { dilakukan release }\end{array}$ & $\sqrt{ }$ & \\
\hline \multirow{3}{*}{3.} & \multirow{3}{*}{$\begin{array}{l}\text { Creating Order } \\
\text { Document } \\
\text { Reference } \\
\text { Notification }\end{array}$} & \multirow{3}{*}{$\begin{array}{l}\text { Pencatatan informasi } \\
\text { operasi kerusakan mesin }\end{array}$} & $\begin{array}{l}\text { Terdapat informasi tentang mesin } \\
\text { yang mengalami kerusakan }\end{array}$ & $\sqrt{ }$ & \\
\hline & & & $\begin{array}{l}\text { Terdapat informasi operasi yang } \\
\text { akan dilakukan terhadap mesin }\end{array}$ & $\sqrt{ }$ & \\
\hline & & & $\begin{array}{l}\text { Terdapat informasi tentang spare } \\
\text { part yang digunakan pada } \\
\text { kegiatan pemeliharaan mesin }\end{array}$ & $\sqrt{ }$ & \\
\hline 4. & $\begin{array}{l}\text { Release Order } \\
\text { Document }\end{array}$ & $\begin{array}{c}\text { Melakukan release } \\
\text { dokumen order sebagai } \\
\text { tanda bahwa dokumen } \\
\text { acuan kegiatan } \\
\text { pemeliharaan mesin telah } \\
\text { siap digunakan. }\end{array}$ & $\begin{array}{l}\text { Dokumen order dapat dilakukan } \\
\text { release }\end{array}$ & $\sqrt{ }$ & \\
\hline 5. & $\begin{array}{l}\text { Creating Order } \\
\text { Confirmation }\end{array}$ & $\begin{array}{c}\text { Konfirmasi terhadap } \\
\text { operasi pemeliharaan mesin } \\
\text { pada dokumen } \text { order yang } \\
\text { telah dibuat sudah selesai } \\
\text { dikerjakan }\end{array}$ & $\begin{array}{l}\text { Pencatatan dokumen order yang } \\
\text { telah dikerjakan }\end{array}$ & $\sqrt{ }$ & \\
\hline 6. & $\begin{array}{l}\text { Creating Technical } \\
\text { Confirmation }\end{array}$ & $\begin{array}{l}\text { Konfirmasi terhadap } \\
\text { operasi pemeliharaan sudah } \\
\text { selesai dikerjakan }\end{array}$ & $\begin{array}{l}\text { Pencatatan dan konfirmasi tentang } \\
\text { operasi pemeliharaan mesin yang } \\
\text { telah dilakukan }\end{array}$ & $\sqrt{ }$ & \\
\hline
\end{tabular}

\subsection{Pembahasan}

Perlu dilakukan identifikasi proses bisnis baik dari aplikasi ERP dan juga proses bisnis yang sedang berjalan dalam perusahaan. Identifikasi tersebut dilakukan untuk memudahkan dalam proses pengaplikasian proses bisnis ke dalam aplikasi ERP [8]. Berdasarkan hal tersebut, penelitian ini terlebih dahulu dilakukan analisis proses bisnis yang berlaku saat ini untuk kegiatan pemeliharaan mesin dan peralatan produksi pada PT. Len Industri (Persero).

Analisis ini dilakukan untuk mengetahui kondisi yang terjadi saat ini termasuk identifikasi form serta laporan yang berlaku dan masalah yang dihadapi ketika proses tersebut berjalan. Ketika sudah memahami proses bisnis eksisting dan permasalahan yang terjadi, maka akan dilakukan analisis proses bisnis yang terdapat pada aplikasi SAP ERP modul Plant Maintenance terkait kegiatan pemeliharaan mesin dan peralatan produksi. Analisis ini dilakukan untuk mengetahui proses bisnis yang dijalankan aplikasi SAP ERP, bagian yang terkait pada proses tersebut, dan dokumen yang mengalir dalam proses tersebut.

Selanjutnya akan dilakukan analisis gap dan fit dengan membandingkan proses bisnis eksisting (dokumen as is) dengan proses bisnis aplikasi SAP ERP (dokumen to be) modul Plant Maintenance. Analisis gap dan fit betujuan untuk menentukan proses serta form yang digunakan untuk kegiatan pemeliharaan mesin dan peralatan produksi akan dilakukan kostumisasi atau standarisasi. 
Kustomisasi adalah melakukan penyesuaian proses atau form eksisting yang tidak dapat diakomodasi oleh aplikasi SAP ERP, sedangkan standarisasi adalah menggunakan format proses atau form yang tersedia pada aplikasi SAP ERP karena proses bisnis eksisting sudah terakomodasi. Keputusan yang terdapat pada analisis gap dan fit pada penelitian ini adalah standarisasi. Hal ini karena setelah dilakukannya perbandingan dokumen as is dan dokumen to be yang telah disusun oleh peneliti dihasilkan semua proses bisnis eksisting kegiatan pemeliharaan mesin dan peralatan produksi dapat diakomodasi oleh proses bisnis SAP ERP sehingga tidak membutuhkan kustomisasi. Dalam hal ini, semua dokumen yang selama ini digunakan dalam kegiatan pemeliharaan mesin dan peralatan produksi pada PT. Len Industri (Persero) dapat diakomodasi dalam dokumen kegiatan pemeliharaan mesin dan perlatan produksi aplikasi SAP ERP. Tabel 2 akan menjelaskan tentang hasil analisis gap dan fit yang telah dilakukan.

Tabel 2. Analisis dengan Gap dan Fit

\begin{tabular}{|c|c|c|c|c|}
\hline No. & Kondisi Saat Ini (As Is) & $\begin{array}{c}\text { Kondisi Sistem ERP-SAP } \\
\text { (To Be })\end{array}$ & Keputusan & Solusi \\
\hline 1. & $\begin{array}{l}\text { Penyimpanan data mesin, suku } \\
\text { cadang mesin, dan peralatan } \\
\text { produksi hanya tersimpan } \\
\text { dalam sebuah dokumen } \\
\text { sehingga rentan akan } \\
\text { kerusakan dan kehilangan. }\end{array}$ & $\begin{array}{l}\text { Pendefinisian mesin, suku } \\
\text { cadang mesin, dan peralatan } \\
\text { produksi harus dilakukan } \\
\text { sebelum memulai aktivitas } \\
\text { kegiatan pemeliharan mesin, } \\
\text { dengan ini data akan } \\
\text { tersimpan dalam database } \\
\text { aplikasi SAP ERP. }\end{array}$ & $\begin{array}{c}\text { Menggunakan aplikasi SAP ERP } \\
\text { modul Plant Maintenance dalam } \\
\text { pendefinisian dan penyimpanan } \\
\text { data mesin, suku cadang, dan } \\
\text { peralatan produksi. }\end{array}$ & Standarisasi \\
\hline 2. & $\begin{array}{c}\text { Pembuatan dokumen } \\
\text { Preventive Maintenance } \\
\text { Scheduling (PMS) sebagai } \\
\text { acuan jadual kegiatan } \\
\text { pemeliharaan mesin dan } \\
\text { peralatan produksi. }\end{array}$ & $\begin{array}{c}\text { Penjadualan kegiatan } \\
\text { pemeliharaan mesin dan } \\
\text { peralatan produksi terdapat } \\
\text { pada Dokumen } \text { Order yang } \\
\text { harus dibuat terlebih dahulu. }\end{array}$ & $\begin{array}{c}\text { Menggunakan aplikasi SAP-ERP } \\
\text { modul Plant Maintenance dalam } \\
\text { penjadualan mesin dan peralatan } \\
\text { produksi. Field yang terdapat pada } \\
\text { dokumen } \text { order dapat mewakili } \\
\text { semua field yang terdapat pada } \\
\text { dokumen PMS. }\end{array}$ & Standarisasi \\
\hline 3. & $\begin{array}{l}\text { Pembuatan dokumen } \\
\text { pengadaan suku cadang mesin } \\
\text { untuk menunjang kegiatan } \\
\text { pemeliharaan mesin dan } \\
\text { peralatan produksi. }\end{array}$ & $\begin{array}{c}\text { Dokumen Purchase } \\
\text { Requisition Dan Purchase } \\
\text { Order digunakan untuk } \\
\text { pengadaan suku cadang mesin } \\
\text { produksi kepada Bagian } \\
\text { Purchasing. }\end{array}$ & $\begin{array}{l}\text { Menggunakan aplikasi SAP-ERP } \\
\text { modul Plant Maintenance dalam } \\
\text { pembuatan dokumen pengadaan } \\
\text { suku cadang mesin produksi. }\end{array}$ & Standarisasi \\
\hline 4. & $\begin{array}{l}\text { Pembuatan dokumen Lembar } \\
\text { Inspeksi Periodik sebagai } \\
\text { pencatatan tindakan yang } \\
\text { dilakukan dalam kegiatan } \\
\text { pemeliharaan mesin dan } \\
\text { peralatan produksi. }\end{array}$ & $\begin{array}{l}\text { Dokumen } \text { Order digunakan } \\
\text { sebagai acuan, pencatatan } \\
\text { riwayat, dan konfirmasi } \\
\text { tindakan yang dilakukan } \\
\text { kegiatan pemeliharaan mesin } \\
\text { dan peralatan produksi. }\end{array}$ & $\begin{array}{l}\text { Menggunakan aplikasi SAP ERP } \\
\text { modul Plant Maintenance dalam } \\
\text { pencatatan tindakan yang } \\
\text { dilakukan dalam kegiatan mesin } \\
\text { dan peralatan produksi. }\end{array}$ & Standarisasi \\
\hline 5. & $\begin{array}{l}\text { Pembuatan dokumen } \\
\text { pengadaan Operator } \\
\text { Pemliharaan eksternal. }\end{array}$ & $\begin{array}{c}\text { Dokumen Purchase Order } \\
\text { digunakan untuk pengadaan } \\
\text { Operator Pemeliharaan } \\
\text { eksternal produksi kepada } \\
\text { Bagian Purchasing. }\end{array}$ & $\begin{array}{l}\text { Menggunakan aplikasi SAP ERP } \\
\text { modul Plant Maintenance dalam } \\
\text { pembuatan dokumen pengadaan } \\
\text { Operator Pemeliharaan eksternal }\end{array}$ & Standarisasi \\
\hline 6. & $\begin{array}{c}\text { Diperlukan pembuatan } \\
\text { dokumen pengajuan kalibrasi } \\
\text { ulang peralatan produksi. }\end{array}$ & $\begin{array}{l}\text { Dokumen order digunakan } \\
\text { sebagai berisi tentang data } \\
\text { peralatan produksi yang akan } \\
\text { dilakukan kalibrasi ulang. }\end{array}$ & $\begin{array}{l}\text { Menggunakan SAP-ERP modul } \\
\text { Plant Maintenance dalam } \\
\text { pembuatan dokumen pengajuan } \\
\text { kalibrasi ulang peralatan produksi. }\end{array}$ & Standarisasi \\
\hline 7. & $\begin{array}{c}\text { Diperlukan pembuatan } \\
\text { dokumen pencatatan hasil }\end{array}$ & $\begin{array}{c}\text { Dokumen inspection lot } \\
\text { digunakan sebagai pencatatan }\end{array}$ & $\begin{array}{l}\text { Menggunakan SAP-ERP modul } \\
\text { Plant Maintenance dalam }\end{array}$ & Standarisasi \\
\hline
\end{tabular}




\begin{tabular}{|c|c|c|c|c|}
\hline No. & Kondisi Saat Ini (As Is) & $\begin{array}{c}\text { Kondisi Sistem ERP-SAP } \\
(\text { To } B e)\end{array}$ & Keputusan & Solusi \\
\hline & $\begin{array}{l}\text { kalibrasi ulang peralatan } \\
\text { produksi. }\end{array}$ & $\begin{array}{l}\text { hasil kegiatan kalibrasi ulang } \\
\text { peralatan produksi. }\end{array}$ & $\begin{array}{c}\text { pencatatan hasil kalibrasi ulang } \\
\text { peralatan produksi. }\end{array}$ & \\
\hline
\end{tabular}

Setelah dilakukannya analisis gap dan fit, maka akan dilakukan analisis risiko terhadap implementasi ERP. Analisis ini dilakukan untuk menghitung besar kemungkinan risiko yang terjadi setelah pengimplementasian ERP dan juga cara mengidentifikasi penanggulangan dari risiko tersebut. Kemungkinan risiko yang digunakan pada analisis ini berdasarkan jurnal analisis risiko postimplementation ERP dengan penyesuaian terhadap kondisi pada PT. Len Industri (Persero).

Setelah itu, akan dipetakan pada matriks tingkatan risiko yang terdiri dari very low, low, medium, high, extreme [9]. Penentuan penanggulangan risiko juga akan berbeda disetiap risiko tergantung tingkatan dari risiko tersebut. Tabel 3 menjelaskan tentang hasil analisis risiko yang telah dilakukan dan Gambar 2 menjelaskan pemetaan analisis risiko kedalam matrtiks tingkatan risiko.

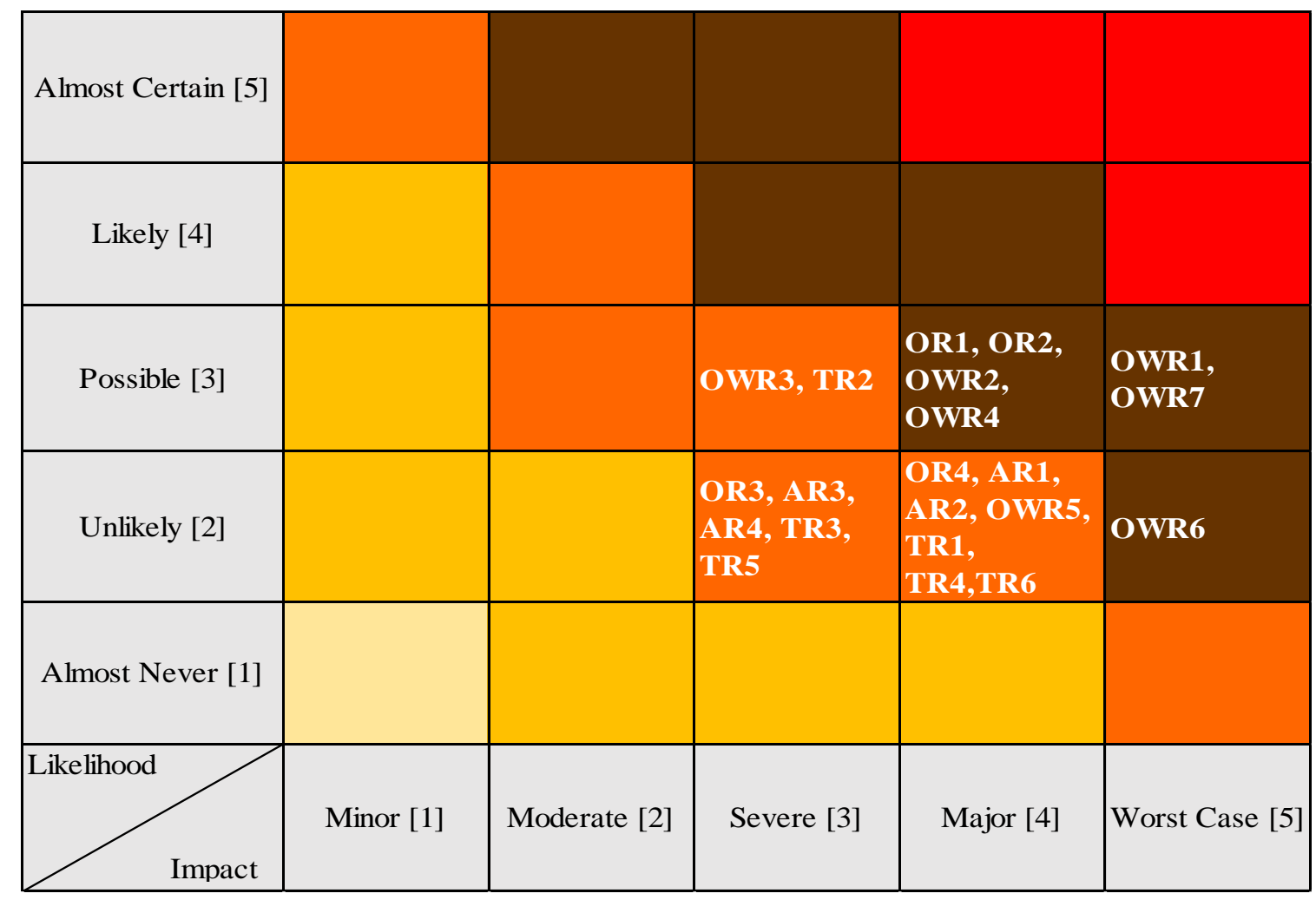

Keterangan:

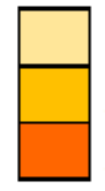

Very low

Low

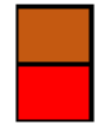

High

Extreme

Medium

Gambar 2. Matriks Tingkatan Risiko 
Tabel 3. Analisis Risiko

\begin{tabular}{|c|c|c|c|c|c|c|c|}
\hline \multirow{2}{*}{ Kode } & \multicolumn{3}{|c|}{ Risiko } & \multirow{2}{*}{$\begin{array}{c}\text { Rata-rata } \\
\text { Likelihood }\end{array}$} & \multirow{2}{*}{ Tingkatan } & \multirow{2}{*}{$\begin{array}{c}\text { Rata-Rata } \\
\text { Impact }\end{array}$} & \multirow{2}{*}{ Tingkatan } \\
\hline & Level 1 & Level 2 & Level 3 & & & & \\
\hline \multirow{4}{*}{ OR } & & & $\begin{array}{l}\text { OR1. Staf Operasional } \\
\text { perusahaan } \\
\text { enggan } \\
\text { menggunakan sistem yang } \\
\text { telah diimplementasikan. }\end{array}$ & 2 & Possible & 3,25 & Major \\
\hline & & $\begin{array}{l}\text { In } \\
\text { General }\end{array}$ & $\begin{array}{l}\text { OR2. Staf operasional } \\
\text { perusahaan salah dalam } \\
\text { memasukan data ke } \\
\text { sistem yang telah } \\
\text { diimplementasikan. }\end{array}$ & 2,25 & Possible & 3 & Major \\
\hline & & & $\begin{array}{l}\text { OR3. Sistem ERP berisi } \\
\text { catatan supplier yang } \\
\text { tidak akurat. }\end{array}$ & 1 & Unlikely & 2,5 & Severe \\
\hline & & $\begin{array}{l}\text { Producti } \\
\text { on Dept. }\end{array}$ & $\begin{array}{l}\text { OR4.Sistem ERP berisi } \\
\text { Bill of Material yang } \\
\text { tidak akurat atau tidak } \\
\text { lengkap. }\end{array}$ & 1,25 & Unlikely & 3,25 & Major \\
\hline \multirow{4}{*}{$\mathrm{AR}$} & \multirow{4}{*}{$\begin{array}{l}\text { Analytical } \\
\text { Risk }\end{array}$} & \multirow[b]{2}{*}{$\begin{array}{l}\text { In } \\
\text { General }\end{array}$} & $\begin{array}{l}\text { AR1.Manager puncak } \\
\text { menolak menggunakan } \\
\text { sistem ERP yang telah } \\
\text { dikembangkan. }\end{array}$ & 1,25 & Unlikely & 3,75 & Major \\
\hline & & & $\begin{array}{lr}\text { AR2.Para } & \text { manager } \\
\text { perusahaan } & \text { menolak } \\
\text { untuk } & \text { memperoleh } \\
\text { informasi yang relevan } \\
\text { dan yang dibutuhkan dari } \\
\text { sistem ERP yang telah } \\
\text { diimplementasikan. }\end{array}$ & 1,75 & Unlikely & 3 & Major \\
\hline & & \multirow{2}{*}{$\begin{array}{l}\text { Proudcti } \\
\text { on Dept. }\end{array}$} & 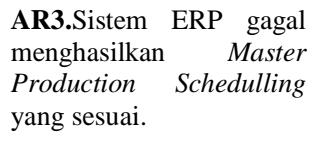 & 1 & Unlikely & 2,75 & Severe \\
\hline & & & $\begin{array}{l}\text { AR4.Sistem ERP gagal } \\
\text { menghasilkan Material } \\
\text { Net Requirement Plan } \\
\text { yang sesuai. }\end{array}$ & 1,25 & Unlikely & 2,5 & Severe \\
\hline \multirow[t]{2}{*}{ OWR } & \multirow[t]{2}{*}{$\begin{array}{l}\text { Organization } \\
\text { al-Wide } \\
\text { Risk }\end{array}$} & $\begin{array}{l}\text { Top } \\
\text { Manage } \\
\text { ment }\end{array}$ & $\begin{array}{lr}\text { OWR1.Manager } & \text { puncak } \\
\text { perusahaan } & \text { tidak } \\
\text { memberikan } & \text { dukungan } \\
\text { penuh } & \text { dalam } \\
\text { pengembangan } & \text { sistem } \\
\text { ERP } & \end{array}$ & 2 & Possible & 4 & Worst Case \\
\hline & & $\begin{array}{l}\text { IS/ERP } \\
\text { Planning }\end{array}$ & $\begin{array}{l}\text { OWR2. Kesalahan dalam } \\
\text { rencana pengembangan } \\
\text { IS/ERP }\end{array}$ & 2,75 & Possible & 3,5 & Major \\
\hline
\end{tabular}




\begin{tabular}{|c|c|c|c|c|c|c|c|}
\hline \multirow{2}{*}{ Kode } & \multicolumn{3}{|c|}{ Risiko } & \multirow{2}{*}{$\begin{array}{c}\text { Rata-rata } \\
\text { Likelihood }\end{array}$} & \multirow{2}{*}{ Tingkatan } & \multirow{2}{*}{$\begin{array}{c}\text { Rata-Rata } \\
\text { Impact }\end{array}$} & \multirow{2}{*}{ Tingkatan } \\
\hline & Level 1 & Level 2 & Level 3 & & & & \\
\hline & & & $\begin{array}{ll}\text { ketidaksesuaian } & \text { dengan } \\
\text { strategi bisnis. } & \end{array}$ & & & & \\
\hline & & & $\begin{array}{lr}\text { OWR3.Para user } & \text { tidak } \\
\text { merasa nyaman untuk } \\
\text { menerima } & \text { dan } \\
\text { memasukan data ke } \\
\text { sistem ERP yang telah } \\
\text { diimplementasikan. }\end{array}$ & 2,5 & Possible & 2,75 & Severe \\
\hline & & & $\begin{array}{lr}\text { OWR4.Masalah yang } & \text { yark } \\
\text { berkaitan dengan } & \text { sistem } \\
\text { ERP tidak } & \text { segera } \\
\text { dilaporan oleh } \text { user } & \text { sistem } \\
\text { kepada } & \text { Bagian } \\
\text { Maintenance } & \text { Sistem. }\end{array}$ & 2 & Possible & 3 & Major \\
\hline & & $\begin{array}{l}\text { System } \\
\text { User }\end{array}$ & $\begin{array}{l}\text { OWR5. Hak kuasa akses } \\
\text { data diberikan pada user } \\
\text { yang tidak mempunyai } \\
\text { hak. }\end{array}$ & 1 & Unlikely & 3,75 & Major \\
\hline & & & $\begin{array}{l}\text { OWR6.Data yang rahasia } \\
\text { dapat diakses oleh orang } \\
\text { yang seharusnya tidak } \\
\text { memiliki hak kuasa akses. }\end{array}$ & 1 & Unlikely & 4,25 & Worst Case \\
\hline & & & $\begin{array}{l}\text { OWR7.Para user (Staf } \\
\text { dan manager) tidak } \\
\text { mendapatkan pelatihan } \\
\text { yang cukup dan berlanjut } \\
\text { tentang pengoperasian } \\
\text { sistem ERP. }\end{array}$ & 2 & Possible & 4 & Worst Case \\
\hline \multirow[t]{5}{*}{ TR } & $\begin{array}{l}\text { Technical } \\
\text { Risk }\end{array}$ & $\begin{array}{l}\text { System } \\
\text { Integrati } \\
\text { on }\end{array}$ & $\begin{array}{l}\text { TR1.Setiap modul dalam } \\
\text { sistem ERP tidak dapat } \\
\text { terlihat integrasinya. }\end{array}$ & 1 & Unlikely & 3,75 & Major \\
\hline & & & $\begin{array}{l}\text { TR2.Sistem yang } \\
\text { terdahulu tidak cocok } \\
\text { dengan sistem ERP yang } \\
\text { telah diimplementasikan. }\end{array}$ & 2,25 & Possible & 2,75 & Severe \\
\hline & & $\begin{array}{l}\text { System } \\
\text { Fault }\end{array}$ & $\begin{array}{lr}\text { TR3.Data yang tidak } \\
\text { valid tidak bisa langsung } \\
\text { terdeteksi oleh sistem } \\
\text { ERP yang telah } \\
\text { diimplementasikan. }\end{array}$ & 1,25 & Unlikely & 2,5 & Severe \\
\hline & & & $\begin{array}{l}\text { TR4.Hardware dan } \\
\text { software mengalami crash } \\
\text { ketika dijalankan. }\end{array}$ & 1,75 & Unlikely & 3,25 & Major \\
\hline & & $\begin{array}{l}\text { System } \\
\text { Maintena } \\
\text { nce and } \\
\text { Revision }\end{array}$ & \begin{tabular}{lr}
\multicolumn{3}{l}{ TR5.Adanya bugs dalam } \\
sistem ERP tidak \\
ditangani dengan cepat \\
oleh Bagian & Maintenance
\end{tabular} & 1,25 & Unlikely & 2,75 & Severe \\
\hline
\end{tabular}




\begin{tabular}{|c|c|c|c|c|c|c|c|}
\hline \multirow{2}{*}{ Kode } & \multicolumn{3}{|c|}{ Risiko } & \multirow{2}{*}{$\begin{array}{c}\text { Rata-rata } \\
\text { Likelihood }\end{array}$} & \multirow{2}{*}{ Tingkatan } & \multirow{2}{*}{$\begin{array}{l}\text { Rata-Rata } \\
\text { Impact }\end{array}$} & \multirow{2}{*}{ Tingkatan } \\
\hline & Level 1 & Level 2 & Level 3 & & & & \\
\hline \multicolumn{8}{|c|}{ Sistem. } \\
\hline & & & $\begin{array}{l}\text { TR6. Data yang outdate } \\
\text { dan terduplikasi dalam } \\
\text { sistem ERP yang telah } \\
\text { diimplementasikan tidak } \\
\text { dihilangkan dengan benar. }\end{array}$ & 1 & Unlikely & 3 & Major \\
\hline
\end{tabular}

Daftar risiko yang tertera dalam Tabel 3 peneliti dapatkan berdasarkan sumber yang digunakan. Sumber tersebut adalah jurnal tentang analisis risiko terhadap implementasi ERP. Selanjutnya peneliti akan mengajukan kuisioner mengenai risiko-risiko tersebut kepada Manajer Produksi dan Koordinator Pengendali Fasilitas Produksi PT. Len Industri (Persero) dengan pembagian dua indikator kuisioner yaitu waktu terjadi (likelihood) dan dampak yang ditimbulkan (impact) dari sebuah risiko.

Setelah terdapat nilai dari keduanya maka akan dirata-ratakan sehingga akan tedapat nilai pada rata-rata likelihood dan rata-rata impact. Kedua rata-rata tersebut memiliki tingkatan untuk nanti dapat dipetakan kedalam matriks tingkatan risiko. Untuk tingkatan likelihood akan digambarkan pada Tabel 4. Hasil ratarata likelihood yang telah dilakukan, tingkatan risiko terdapat pada tingkatan possible (kadang-kadang) dan unlikely (jarang). Sedangkan untuk tingkatan impact akan digambarkan pada Tabel 5.

Tabel 4. Tingkatan Likelihood

\begin{tabular}{ccc}
\hline Tingkatan & Deskripsi \\
& Keterangan & Rata-Rata Frekuensi Likelihood \\
\hline Almost Never & Tidak pernah & $<1$ \\
Unlikely & Jarang & $1,00-1,99$ \\
Possible & Kadang-kadang & $2,00-2,99$ \\
Likely & Sering & $3,00-3,99$ \\
Almost Certain & Selalu terjadi & $>4$ \\
\hline
\end{tabular}

Tabel 5. Tingkatan Impact

\begin{tabular}{ccc}
\hline & & \\
Tingkatan & Keterangan & Rata-Rata Frekuensi Impact \\
\hline Minor & Sangat kecil & $<1$ \\
Moderate & Kecil & $1,00-1,99$ \\
Severe & Cukup Besar & $2,00-2,99$ \\
Major & Besar & $3,00-3,99$ \\
Worst Case & Sangat Besar & $>4$ \\
\hline
\end{tabular}


Hasil rata-rata impact yang telah dilakukan, tingkatan risiko berada dalam tingkatan severe (cukup besar), major (besar), wost case (sangat besar). Setelah didapat tingkatan dari likelihood dan impact dari masingmasing risiko maka selanjutnya akan dilakukan pemetaan risiko ke dalam matriks risiko yang digambarkan pada Gambar 2. Matriks tingkatan risiko terdiri dari dua yaitu sumbu x yang merupakan tingkatan impact dan sumbu y yang merupakan tingkatan likelihood. Sementara itu matriks tersebut memiliki lima tingkatan risiko yang dibagi menjadi lima warna yaitu very low, low, medium, high, dan extreme. Semakin tinggi tingkatan risiko pada matriks tersebut maka semakin perlu perhatian dan penanggulangan yang ekstra.

\section{Kesimpulan}

Kesimpulan yang diperoleh dari penelitian ini adalah sebagai berikut:

1) Aplikasi SAP ERP modul Plant Maintenance dapat dikonfigurasikan sesuai dengan kebutuhan PT. Len Industri (Persero) menggunakan metode ASAP yang memungkinkan pengembang untuk banyak melakukan interaksi kepada stakeholder sehingga dapat melakukan perbaikan secara terus-menerus. Hasil pengembangan aplikasi SAP ERP modul Plant Maintenance untuk kegiatan pemeliharaan mesin dan peralatan produksi dapat dilihat dari beberapa aspek yaitu sebagai berikut:

a. Berdasarkan analisis risiko yang telah dilakukan, risiko yang kemungkinan terjadi terkait pengembangan aplikasi SAP ERP ini berada dalam tingkatan high dengan kategori operational risk dan oragnitational-wide risk. Untuk menurunkan kemungkinan terjadinya risiko tersebut dibutuhkan perbuhahan budaya kerja dan dukungan penuh dalam pengembangan aplikasi SAP ERP.

b. Dapat mencatat seluruh dokumentasi kegiatan pemeliharaan mesin dan peralatan produksi karena semua proses bisnis menggunakan Dokumen Order dan Notification sebagai pencatat penyebab kerusakan, operasi pemeliharaan dan spare part yang digunakan.

c. Dapat menyediakan pemberitahuan status ketersediaan mesin yang terdapat pada Dokumen Order sehingga status ketersediaan mesin dapat dilihat secara real time.

2) Aplikasi SAP ERP modul Plant Maintenance dapat terintegrasi dengan bagian lain yang terkait pada PT. Len Industri (Persero) sehingga terjadi penghematan waktu dalam setiap proses lintas bagian. Bentuk integrasi yang terjadi yaitu sebagai berikut:

a. Bagian Perencanaan dan Pengendalian Produksi akan terintegrasi terkait pemberian informasi status ketersediaan mesin dan pengadaan spare part serta Operator Pemeliharaan eksternal.

b. Bagian Kalibrasi Peralatan akan terintegrasi terkait kegiatan kalibrasi ulang peralatan produksi.

c. Bagian Logisitik akan terintegrasi terkait Goods Receipt spare part.

\section{Daftar Rujukan}

[1] PT. Len Industri (Persero). (2014). Annual Report 2014. Retrieved from www.len.co.id/len_web/ar

[2] Stair, R. M., \& Reynolds, G. W. (2014). Principles of Information Systems. Boston: Course Technology.

[3] Monk, E., \& Wagner, B. (2013). Concepts in Enterprise Resource Planning. Boston: Course Technology.

[4] Addo-Tenkorang, R., \& Helo, P. (2011). Enterprise Resource Planning (ERP): A Review Literature Report. Proceedings of the World Congress on Engineering and Computer Science 2011 Vol II.

[5] Vaman, J. G. (2008). ERP in Practice. New Delhi: Tata McGraw-Hill Publishing Company Limited

[6] Liebstuckel, K. (2011). Plant maintenance with SAP. Boston: Galileo Press Inc.

[7] Anderson, G., \& Larocca, D. (2011). Sams Teach Yourself SAP in 24 Hours. Pearson Education, Inc.

[8] Rispianda., dkk. (2014). Penerapan Sistem Open Source Enterprise Resource Planning pada Perusahaan Elektronika. Jurnal Online Institut Teknologi Informasi.

[9] Carey, M., \& Curtis, P. (2012). Risk Assessment in Practice. Committee of Sponsoring Organizations of the Treadway Commission. 